\title{
JORNAL ESCOLAR: PRODUÇÃO TEXTUAL, INTERATIVIDADE E O USO DAS TICS NAS ESCOLAS
}

\author{
Cassiano Miglia Vacca, UCS, cassianomv@yahoo.com.br \\ Maria de Fátima Webber do Prado Lima, CCET/UCS, mfwplima@ucs.br
}

\begin{abstract}
Resumo. O Jornal Escolar pode ser visto como uma ferramenta apropriada para auxiliar os professores de Língua Portuguesa a superarem o desinteresse dos alunos pela leitura e seu despreparo com a escrita. Ele visa promover a produção escrita significativa e voltada para o contexto social e histórico vivido pelo estudante, levando-o à condição de sujeito produtor de conhecimentos. A implantação do projeto na Escola Municipal Padre Josué Bardin de Nova Prata/RS demonstrou que uma metodologia que integra tecnologia, leitura e produção textual é um caminho pedagógico possivel e viável, desenvolvendo o conhecimento por meio de um trabalho interdisciplinar, colaborativo e online.
\end{abstract}

Palavras chaves: Leitura e Produção Textual, Tecnologias de Informação e Comunicação, Produção Colaborativa e Interdisciplinar, Jornal Escolar.

\section{SCHOOL NEWSPAPER: TEXTUAL PRODUCTION, INTERDISCIPLINARITY AND USE OF ICT IN SCHOOLS}

\begin{abstract}
The School Newspaper can be seen as a tool appropriate to help teachers of Portuguese Language exceed the disinterest of the students for the reading and its disorganization with the writing. It aims to promote significant written production and focused on the social and historical context lived by the student, taking him to the status of the producing knowledge. The project implantation at Padre Josue Bardin School from Nova Prata/RS demonstrated that a methodology that integrated technology, reading and text production is a possible and viable pedagogical way, developing the knowledge by interdisciplinary, collaborative and online work.
\end{abstract}

Keywords: Reading and textual production, Information Technologies and Communication, Collaborative and Interdisciplinary Production; School Newspaper.

\section{Introdução}

$\mathrm{O}$ ato de ler e escrever perpassa todas as áreas do conhecimento e se torna fundamental dentro e fora da escola, fornecendo ao aluno ferramentas importantes para a aquisição de novos conhecimentos, para a comunicação e livre expressão nos mais variados contextos. O simples e puro exercício de escrever, muitas vezes, sem vinculação com o contexto do aluno podem desmotivá-lo, levando-o a encarar os processos de leitura e escrita como mais uma atividade de sala de aula, dissociada de sua vida. Neste contexto, a utilização do Jornal Escolar pode-se tornar um meio para o desenvolvimento de uma 
dinâmica geral na escola. Se pedagogicamente bem direcionado, possibilita o docente realizar uma ruptura com práticas pedagógicas rotineiras (SANTOS; PINTO, 1992).

Uma proposta pedagógica que vise trabalhar a Língua Portuguesa associada ao uso do Jornal no contexto escolar, sob a luz das novas Tecnologias de Informação e Comunicação (TICs) é um desafio. Um desafio que pretende promover a leitura e a produção textual de forma significativa, num espaço de interdisciplinaridade, trabalho colaborativo e ligado à realidade tecnológica vivenciada pelos estudantes. $\mathrm{O}$ artigo proposto está organizado em 6 seções. Inicialmente a seção 2 apresenta a fundamentação teórica utilizada para embasar este projeto. Na seção 3 é descrita a metodologia utilizada para o desenvolvimento do projeto. A seção 4 descreve os resultados obtidos. Por fim, a seção 5 conclui o estudo realizado e aponta resultados preliminares.

\section{Fundamentação Teórica}

As dificuldades apresentadas pelos alunos diante do uso da Língua Portuguesa, sobretudo no que diz respeito à produção escrita, ressaltados pelos erros ortográficos e de sintaxe comumente observados em redações, demonstram um processo de ensino e aprendizagem fragilizado.

Travaglia (2009) e Gomes (2002) afirmam que os erros recorrentes encontrados nas escritas dos alunos é um reflexo de dois fatores fortemente arraigados no contexto de sala de aula: a forma descontextualizada e vazia de sentido com que a gramática é ensinada e como o professor lida com os erros. Cagliari (2009) propõe que a melhor forma de permitir que o aluno avance na sua apropriação da língua escrita, é mapeando, de forma consistente, os erros mais frequentes nas produções e, diante disso, partir para a intervenção pedagógica. Cagliari (2009) cita como principais erros na escrita: transcrições fonéticas, uso indevido de letras, hipercorreção, modificação da estrutura segmental das palavras, juntura intervocabular e segmentação, uso indevido de maiúscula e minúscula, omissão de acentuação gráfica e problemas sintáticos.

O Jornal no contexto escolar é uma metodologia que trabalha a importância e a utilização da língua escrita para o contexto social, bem como no espaço virtual, fazendo com que o aluno escreve e reescreva, avançando em sua produção escrita. $\mathrm{O}$ jornal abre novas possibilidades de trabalhar o texto, levando o estudante a exercitar várias operações para processar informações em fluxo contínuo nos mais variados gêneros textuais: comentar, explicar, opinar, selecionar, seriar, discriminar, comparar, induzir, deduzir, sintetizar, classificar, interpretar, justificar, concluir, etc..

Segundo Faria (2009, p. 19) uma proposta pedagógica que pretende trabalhar com o Jornal precisa preparar alunos e professores com atividades como análise de um jornal, leitura e estudo dos textos publicados e visita a uma empresa jornalística. No processo de produção, Faria e Zanchetta Jr. (2011, p. 144) destacam a importância da criação da equipe de redação, a definição dos participantes que irão colaborar com o jornal, a definição da pauta e de suas responsabilidades, a nucleação do material produzido e coletado para as fases finais de diagramação, impressão e distribuição e a definição da organização gráfica (tamanho das letras e tipologia, ilustrações, etc.).

Neste trabalho todo, a ação do professor é fundamental para o êxito do jornal, para o efetivo trabalho colaborativo e, principalmente, como avaliador da prática a fim de verificar se a mesma está promovendo processo de aprendizagens significativas entre os participantes.

Para que isso ocorra, o trabalho em grupo é fundamental. Para Lévy (1998) é a coletividade que proporciona inteligência ao sujeito. Bordenave (1977) coloca que, durante a realização de um trabalho em grupo, os participantes acabam assumindo 
funções diferentes, complementares entre si que auxiliam na produtividade do grupo: os inovadores que sugerem novas ideias, os estimuladores que entusiasmam o grupo na realização das tarefas, os coletores de informações, os avaliadores críticos, que analisam o desempenho do grupo, os coordenadores e os relatores. Na área de aprendizagem, diversos estudiosos estudaram a relação do processo de aprendizagem com o trabalho em grupo. A epistemologia genética, de Piaget (1956), forneceu elementos para o estudo da formação operatória dos grupos. Para ele, a cooperação é a coordenação de pontos de vista ou de ações oriundas de diversos indivíduos, tornando-se o ponto de partida de diversas ações na constituição e no desenvolvimento da lógica. Vygotsky $(1979,1989,1998)$ centrou seus estudos na gênese dos processos psicológicos humanos (funções psicológicas superiores) em seu contexto social, mostrando a importância do trabalho em grupo e a possibilidade de evolução pelas relações sociais. Freinet $(1969,1976)$ estudou dinâmicas de trabalho em grupo que propiciassem o desenvolvimento do indivíduo na perspectiva de que o sujeito deve realizar atividades relacionadas com a realidade. Freinet $(1969,1976)$ pregou o cultivo do respeito e da livre-expressão utilizando a valorização das qualidades individuais e do trabalho em grupo. Em sua pedagogia, o aprendiz possui liberdade para exercer atividades individualmente, em seu ritmo, mas também deve participar ativamente do grupo.

Além do trabalho em grupo, outro aspecto que deve ser considerado é a interdisciplinaridade. Segundo Paviani (2005), a interdisciplinaridade faz com que os programas de ensino sejam organizados em torno de problemas científicos e de caráter pedagógicos que considerem as necessidades da sociedade e os interesses dos alunos. Para Paviani (2005), a utilização da interdisciplinaridade é necessária para auxiliar na formação de profissional flexível e adequada para o exercício de novas profissões. Santomé (1998) também relaciona a interdisciplinaridade com o trabalho, ressaltando que a vida profissional exige uma plurivalência de informações e que o aluno deve estar preparado para enfrentar as múltiplas exigências profissionais.

Fazenda (2009) ressalta que para realizar um projeto interdisciplinar, o projeto inicial deve estar definido de forma clara, coerente e detalhado, para que todas as pessoas envolvidas conheçam o projeto. Paviani (2005) salienta que não basta apenas definir a integração dos educadores e das disciplinas, mas é necessário explicitar em que consiste essa integração e de modo ela é viabilizada.

As TICs são fundamentais para o andamento de um bom projeto de produção de um jornal escolar. As TICs contribuem em dois momentos importantes: na produção do jornal, quando permite ao aluno utilizar softwares de edição de texto para a produção escrita, de edição e arquivamento de imagens para gerenciar as fotografias a serem utilizadas e de arte e diagramação, para o desenvolvimento gráfico do material. Num segundo momento, permite, também, por meio de ferramentas para a criação de e-books (que podem ser folheados no formato online) e de site no formato blog, uma abertura para a divulgação sem fronteiras do trabalho produzido, permitindo possibilidades infinitas de interação com outros leitores-internautas, usuários da internet.

\section{Materiais e Métodos}

A Escola Municipal de Ensino Fundamental Padre Josué Bardin está localizada no Bairro São João Bosco, no município de Nova Prata/RS. Situada num bairro populoso e geograficamente afastado do perímetro urbano central da cidade, a Escola é vista, tanto pela comunidade como pelos seus estudantes, como um importante espaço comunitário de realização de inúmeras atividades paralelas aos estudos. Oficinas de Letramento e Matemática, de Confecção de Jogos, Xadrez, Iniciação em Libras, Música, Dança, Artesanato e Projetos Culturais como o de resgate da História do bairro através de 
fotografias são oferecidos pela escola. Isso faz com que os alunos a frequentem constantemente durante o contraturno escolar. Portanto, quando o projeto de realização de um jornal escolar interativo foi apresentado, inicialmente para a equipe diretiva e após para os alunos, o mesmo foi muito bem aceito pela comunidade escolar.

A realização de um Jornal Escolar fez com que os estudantes participassem de oficinas de produção textual, pautadas numa metodologia de uso das novas tecnologias de informação e comunicação, com o objetivo de ressignificar o uso da Língua Portuguesa, aperfeiçoando-se no estudo da mesma. Partindo desta premissa, os encontros da oficina iniciaram com a apresentação da proposta, bem como o estudo e análise do universo jornalístico. Textos sobre a importância do jornal na sociedade e como funcionam as etapas de produção do mesmo foram debatidos pelos alunos. A análise de jornais locais, bem como as intervenções na internet (por meio de sites e redes sociais) dos grandes jornais foram os assuntos abordados durante os dois primeiros encontros. A visita ao semanário local, o Jornal Popular, complementou esta primeira etapa de estudos. $\mathrm{Na}$ oportunidade, os alunos conheceram na prática todo o processo de criação de uma edição de jornal, passando pela fotografia e redação, diagramação e o processo de impressão e distribuição.

Após o momento de estudo e análise, o grupo, em reunião durante o quarto encontro da oficina, criou o nome do Jornal e um slogan para o mesmo. Definiram, também, a primeira pauta: quais as principais notícias e seções que deveriam fazer parte do jornal recém-criado. Por opção própria, grande parte dos estudantes trabalhou em duplas. Cada dupla ficou responsável por uma ou duas seções ou notícias, escolhidas de acordo com a afinidade dos mesmos com os assuntos. Elaboraram, também, o blog e seu respectivo endereço para a vinculação do periódico na Internet.

Os demais encontros que se seguiram foram dedicados à produção escrita e gerenciamento de imagens. Professores, pais e equipe diretiva e de coordenação pedagógica acompanharam direta e indiretamente o trabalho dos alunos, fornecendo informações, fotografias e demais materiais e, principalmente, assessorando os mesmos durante o processo de produção escrita. A busca de informações, escrita, reescrita e revisão foram etapas pelas quais os estudantes passaram para chegarem ao produto final - uma redação de cunho jornalístico, respeitando o gênero textual escolhido.

Por fim, nos últimos encontros do projeto, os alunos planejaram a diagramação do jornal, incluindo as noticias e seções a serem vinculadas ao mesmo, além das suas respectivas colocações nas páginas. Pronto e aprovado por todos, o jornal foi enviado à gráfica para a arte final e impressão. Doze encontros foram realizados e contou, sempre, com a participação ativa dos estudantes. O grupo, que havia iniciado com 11 participantes, encerrou o projeto com 13 componentes. As etapas de realização do Jornal Escolar foram definidas a partir das sugestões pedagógicas de Faria (2009) e Faria e Zanchetta Jr. (2011).

A fim de melhor gerenciar a produção textual e o arquivamento de textos e imagens, os alunos criaram uma conta de e-mail e utilizaram a ferramenta online do Google Drive. No Google Drive, os alunos digitaram, revisaram e reescreveram suas escritas e, também, arquivaram fotografias e desenhos e os compartilharam com os demais colegas da equipe. Foi utilizado o software Gimp para o corte e ajuste das fotografias. O software de desenho vetorial Draw Plus auxiliou no planejamento da diagramação do jornal.

Para o trabalho interativo na Internet, foram utilizadas as ferramentas virtuais do Tumblr (para a criação do blog) e do Youblisher (para a criação do FlipBook do jornal). Os alunos atuaram, também, como colaboradores de conteúdo para a FanPage da Escola no Facebook. Todos os softwares e serviços online foram utilizados a partir da política digital do software livre para fins educacionais (BITENCOURT; SANTOS, 2004). 
A fim de promover a avaliação constante do trabalho, os professores de Língua Portuguesa da escola foram convidados a avaliar os alunos integrantes do jornal em dois momentos: no início e no final do projeto, para pautar possíveis progressos e avanços no campo da produção escrita. Aos docentes, foi apresentada uma planilha contendo os principais erros em Língua Portuguesa cometidos pelos estudantes do Ensino Fundamental, de acordo com Cagliari (2009). Tal planilha quantificou o grau de frequência em que os erros aconteceram na produção escrita no início e término das oficinas realizadas. Além deste instrumento avaliativo, optou-se, também por uma metodologia mais qualitativa, promovendo várias conversas entre professores, coordenação pedagógica e equipe diretiva da escola a fim de mapear a intervenção pedagógica.

Os alunos, por sua vez, também avaliaram a sua prática e a do projeto por meio da ferramenta virtual do Webfólio. Em sua conta no Google Drive, os discentes mantiveram, durante a realização das oficinas, um arquivo de texto no qual foram registrando suas impressões sobre o trabalho realizado.

A edição número um do Jornal Escolar da Bardin - Bardin no Comando: as principais notícias da nossa escola, tem seções como editorial, charge, opinião, entrevistas, dicas de leitura, esportes e cruzadinhas, distribuídas ao longo de quatro páginas totalmente produzidas pelos alunos com a participação de três professores (que também quiseram contribuir com matérias) e de uma escritora (que foi entrevistada pelos alunos). Na versão online do blog, matérias estendidas e com mais fotografias, além de entrevistas especiais e outros materiais informativos (Figura 1). O jornal online pode ser consultadono endereço: http://jebardin.tumblr.com/.

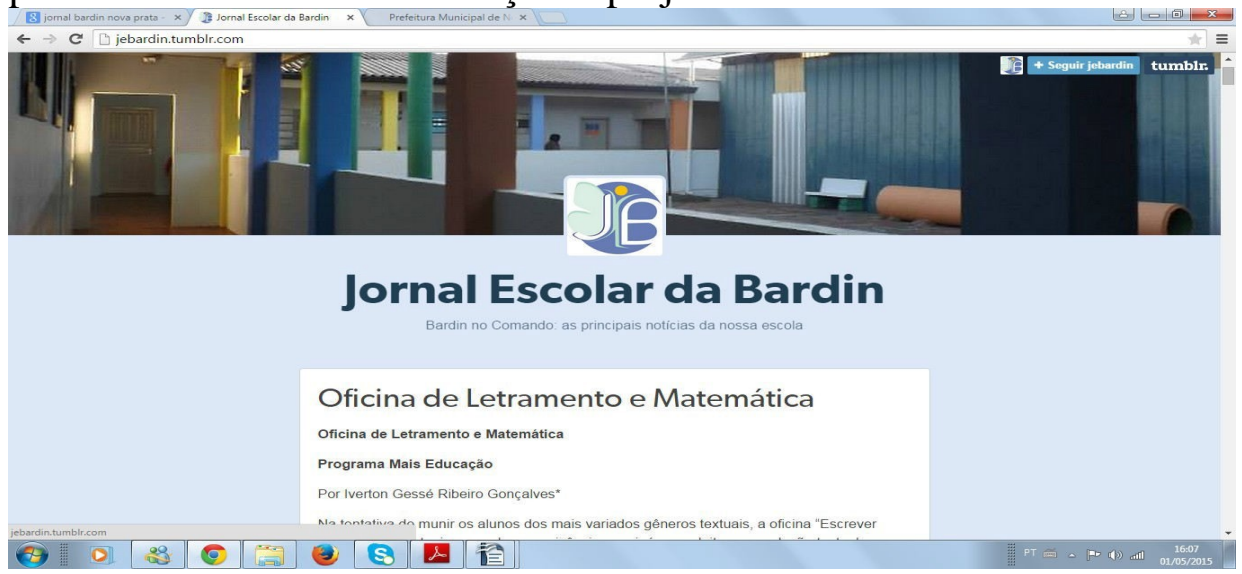

Figura 1 - Jornal Escolar da Bardin

\section{Resultados Obtidos}

O trabalho de elaboração de um jornal escolar interativo e interligado com as novas tecnologias de informação e comunicação com os alunos do $6^{\circ}$ ao $9^{\circ}$ da Escola Municipal Padre Josué Bardin, buscou aproximar a produção textual do aluno. Esta aproximação permitiu, aos discentes, ver a importância dos mais diversos gêneros textuais aplicados numa experiência real de uso da escrita no cotidiano.

Além disso, outra intenção do trabalho foi envolver os alunos, de forma ativa, no uso das novas tecnologias de informação e comunicação. Para isto, buscou-se elaborar o jornal na versão impressa (totalmente feita via uso de software de edição de texto e fotografia) e virtual (via blog e FlipBook). 
Enfim, buscou-se, com o uso da tecnologia associada à produção textual e sob a orientação de professores da área de Língua Portuguesa e enriquecida pelas demais áreas do conhecimento, motivar o aluno a aperfeiçoar-se mais no estudo da sua escrita através de uma experiência concreta de produção de conhecimentos. Uma experiência na qual ele saiu da condição de expectador passivo da língua para a de um sujeito ativo. Um sujeito que opina, informa, pesquisa e se expressa por meio da escrita.

Esta nova situação, em que o aluno se vê numa condição de sujeito produtor de conhecimentos, por vezes, acaba por assustá-lo num primeiro momento. Com a equipe de treze estudantes que participaram da produção do jornal escolar, não foi diferente. Os mesmos, diante da condição de responsáveis por redigir matérias e seções específicas, viram-se impulsionados a buscar informações para agregar ao conteúdo a se escrito. Este processo de busca envolveu professores, a comunidade escolar e exigiu novas leituras. Exigiu, também, a seleção da informação e a relação dos dados coletados para a elaboração do texto de cunho jornalístico.

\subsection{O Processo de Produção Textual dos Alunos}

O processo de busca, pesquisa, compreensão e relação para uma posterior escrita, causou, inicialmente, certo desconforto entre os estudantes. Como bem pontuou uma aluna em seu Webfólio, ao avaliar o projeto:

Aluna A: "Eu achei o começo um pouco difícil e eu não sabia o que fazer. Mas depois eu gostei. Eu achei o jornal muito legal e interessante para mim e para nós porque aprendemos coisas novas".

A busca pelas informações e a posterior produção textual foram dois momentos que intimidaram os alunos. Muitos deles, em suas falas como: "Será que vou conseguir", "Vai ser meio difícil" ou "Vamos ter ajuda para fazer isto", demonstraram uma insegurança inicial em relação à proposta lançada. Tamanho foi o desconforto que os mesmos sugeriram que toda a produção escrita fosse realizada durante a oficina.

Uma aluna sugeriu, na reunião de pauta, que todos tivessem um caderno a ser utilizado na pesquisa das informações para, depois, montar o texto final no computador: "Aí nessa parte o professor ajuda a gente, né?". Outra sugestão dos alunos foi a realização do trabalho em duplas. Os mesmos aceitaram a condição de fazer mais de uma matéria de jornal, desde que trabalhassem em grupos. Poucos estudantes (apenas dois) aventuraram-se sozinhos.

Tal medo reflete a insegurança diante do uso da língua escrita. Como bem pontua Cavalcanti (2010), as redações escolares desconectadas da realidade reforçam uma compreensão inadequada da escrita, uma visão artificial do ato de escrever. Quando o aluno se depara na condição que exige dele a produção de textos de verdade, isto é, que são produzidos para circularem fora da escola, o mesmo passa a acreditar que não consegue escreve porque não tem um talento natural. Não tem o "dom da escrita".

No entanto, o desconforto inicial foi sendo amenizada ao longo das oficinas quando perceberam que, com o conteúdo em mãos e comprometidos com a sua matéria, conseguiram, aos poucos, redigir o texto. E o trabalho em duplas foi fundamental para isto, uma vez que os alunos auxiliavam-se durante o processo de escrita. Somando-se a isto, o fato de escrever para o jornal, ou seja, não somente para um simples exercício artificial de sala de aula, fizeram com que se comprometessem com o a sua produção, exigindo de si mesmos um resultado satisfatório. Como falou um aluno durante a oficina, ao solicitar auxílio para revisar seu texto: "Tem certeza que ficou legal assim? Será que o pessoal vai gostar? Não vamos passar vergonha, né?".

Quanto aos erros mais frequentes apresentados pelos alunos durante a produção escrita, os mesmos definem o que os professores de Língua Portuguesa da escola já mencionaram durante a sua avaliação inicial dos discentes, no início da realização do projeto de elaboração do jornal. Avaliação esta que teve como base os erros mais corriqueiros entre os discentes do Ensino Fundamental, de acordo com Cagliari (2009). 
Convidados a avaliar os estudantes, a fim de mapear suas principais dificuldades no contato com a escrita (Tabela 1), os professores destacaram, de forma unanime, nas planilhas de avaliação apresentadas, dois aspectos mais corriqueiros: a transcrição fonética (quando o aluno acaba por transcrever a própria fala no ato da escrita) e os problemas sintáticos (concordância verbal e nominal, coesão, coerência e ordenação de frases e textos). Erros como o de modificação na estrutura segmental das palavras e de omissão de acentuação gráfica também foram apontados como problemas secundários.

Tabela 1 - Resultados da Avaliação dos Erros Recorrentes na escrita dos estudantes

\begin{tabular}{l|c|c|}
\hline \multicolumn{1}{|c|}{ Erros recorrentes em Língua Portuguesa } & $\begin{array}{c}\text { Alunos que } \\
\text { apresentara } \\
\mathbf{m} \text { o } \\
\text { problema }\end{array}$ & $\begin{array}{c}\text { Alunos que apresentaram } \\
\text { avanços ao término do projeto }\end{array}$ \\
\hline Transcrição da fala na escrita & 11 & 6 \\
\hline Uso indevido de letras & 3 & 1 \\
\hline Hipercorreção & 2 & 0 \\
\hline Modificação na estrutura segmental das palavras & 5 & 3 \\
\hline Juntura intervocabular e segmentação & 4 & 2 \\
\hline Uso indevido de maiúscula e minúscula & 2 & 2 \\
\hline Omissão de acentuação gráfica & 5 & 7 \\
\hline Problemas Sintáticos & 11 & $X$ \\
\hline Regras e metas & $\mathrm{X}$ & 2 \\
\hline
\end{tabular}

Fonte: o Autor

Os resultados da avaliação feita demonstram que os alunos apresentaram alguns avanços, apesar do curto tempo de duração do projeto que, infelizmente, impede um trabalho mais aprofundado, permanente e consistente no uso da Língua Portuguesa. Mesmo assim, como é possível observar nos dados pontuados, os problemas sintáticos de ausência de concordância verbal e nominal, coesão, coerência e ordenação de frases e textos obtiveram bons avanços. Dos onze estudantes participantes, sete apresentaram alguma melhoria após um mês de trabalhos intensos na oficina de produção do jornal.

Lógico, como bem destacaram os docentes, os avanços foram significativos, mas ainda são tênues. Muito ainda há que se trabalhar para que os discentes desenvolvam uma produção textual com mais qualidade. Mesmo assim, os dados demonstram que houve um avanço na apreensão da língua portuguesa, sobretudo dos problemas mais recorrentes nos textos dos alunos. Isto prova que um trabalho significativo, no qual se produza textos num e para um contexto social e histórico vivido pelo aluno, se implantado em longo prazo pela escola, tende a apresentar resultados ainda mais positivos.

Além disso, segundo os professores, tais resultados também demonstram que os alunos, sobretudo das séries finais do Ensino Fundamental, sentem-se pouco atraídos pela Língua Portuguesa. Apesar das tentativas em promover ações em prol do incentivo à leitura, para que tenham maior repertório de exemplos para compreender melhor a língua e, assim, utilizá-la com maior propriedade, poucos têm o hábito de ler. E isto se reflete diretamente no ato de escrever.

Como bem pontuaram os docentes da área da linguagem, durante reunião ao final do projeto, problemas como a transcrição da fala na escrita, uso indevido de letras e demais aspectos ligados à ortografia das palavras não são problemas preocupantes, pois são reflexos da falta de prática em escrever algumas palavras. O problema maior encontra-se na produção textual, sobretudo na dificuldade que os alunos têm de ordenar ideias ao longo do texto e fazer isto com certa coesão e coerência. Diante disso, destacaram a importância de projetos pedagógicos como a da criação de um jornal escolar, pois permite aos alunos experimentarem o impacto social da escrita e, principalmente, a necessidade de uma redação bem estruturada, com ideias organizadas e coesas para que a função comunicativa entre escritor e leitor aconteça. 
Portanto, o trabalho de escrita, reescrita e revisão ao longo das oficinas, e que contou com a participação dos professores, foi fundamental para a criação de um ambiente de ensino e aprendizagem favorável, no qual os estudantes puderam compreender, de forma mais consistente, a importância de uma boa estruturação textual, com início, meio e fim, interligados e coesos em seu significado.

Sendo assim, os docentes, novamente, foram unanimes em destacar que um projeto, como o da criação de um jornal escolar, que visa promover a produção escrita pautada na sua funcionalidade diante do contexto social, necessita virar um plano anual, com cronograma de atividades bem definido e que conte com a participação de todos os alunos e professores. Certamente, os ganhos no aperfeiçoamento e estudo da Língua Portuguesa seriam ainda mais significativos.

Apesar das dificuldades, do medo e da baixa autoestima inicial dos alunos quanto ao ato de escrever, com a conclusão das redações sentiu-se, na equipe, mais que um alívio - um sentimento de satisfação e orgulho diante do texto produzido. Como coloca uma aluna em seu Webfólio:

Aluna B: "E sobre a redação eu não estava muito a fim de fazer porque era difícil. Só que agora, eu gostei do que escrevi. Eu achei muito importante e interessante saber sobre o esporte na escola".

\subsection{O Trabalho Colaborativo}

Além do trabalho com a escrita, outro aspecto importante a ser salientado consiste no ambiente colaborativo que exigiu dos alunos uma postura de trabalho em equipe. Mesmo que as produções tenham ocorrido de forma individual ou em duplas, as decisões de pauta e que afetaram o jornal como um todo, eram tomadas em equipe. A intervenção do grupo aconteceu durante todas as oficinas. Os alunos compartilhavam os textos produzidos e as fotografias, abrindo brechas para sugestões e opiniões sobre o que estava sendo redigido. $\mathrm{O}$ resultado foi positivo, como descreve uma aluna:

Aluna C "Eu gostei de participar muito do jornal. Teve muita conversa e pessoas, mas é muito divertido. Tem algumas discussões, mas não é nada demais. Espero que o ano que vem seja assim de novo, porque é legal e eu adorei."

Mesmo com alguns desentendimentos ou contradições entre colegas, para os alunos a convivência não foi prejudicada. Ao contrário, foi divertida e permitiu que se criasse, a partir do coletivo, uma unidade concentrada em busca de um objetivo comum que era produzir o jornal da escola. O diálogo e o debate, mesmo que tenso por vezes, fomentou o sentimento de pertencimento ao grupo e a importância do comprometimento de todos para o sucesso do projeto (PRIMO; RECUERO, 2003, p. 3).

As colaborações externas ao grupo também foram cruciais e auxiliaram na realização do jornal. Três professores, a convite dos alunos, participaram do jornal com textos. Uma escritora também contribuiu dando uma entrevista especial para uma dupla que elaborou as perguntas. Professores das mais diversas áreas foram procurados pelos alunos na busca por informações e foram prontamente solícitos. Tal atitude dos docentes e da escritora que, ao interagir com o projeto, preocuparam-se em produzir um material de qualidade para o jornal, reforçou nos alunos a importância do trabalho que estavam realizando, levando-os a comprometerem-se ainda mais com as atividades a serem realizadas.

O jornal mobilizou a comunidade escolar que se identificou com o trabalho e colaborou para que o mesmo acontecesse satisfatoriamente. $\mathrm{O}$ jornal foi uma construção do aluno, mas realizada através do trabalho mútuo de todos dentro uma proposta colaborativa e interdisciplinar, resultando numa material rico em diversidade de gêneros textuais. O conteúdo do jornal demonstrou um vínculo forte de pertencimento ao seu respectivo contexto, no qual e para o qual foi criado e desenvolvido (FARIA; 
ZANCHETTA JR., 2011, p. 141).

Além disso, cabe ressaltar que o uso das novas tecnologias de informação e comunicação, juntamente com um trabalho voltado para a realidade contextual da própria escola e dos alunos, foram marcantes para despertar o interesse pelo assunto da produção textual. Mesmo com as agruras causadas pelos equipamentos de informática defasados, obrigando o grupo a mudar do laboratório de informática para a sala de recursos multifuncionais, os alunos demonstraram grande interesse em aprender sobre como trabalhar com a digitação no editor de texto e depois arquivá-lo na nuvem do Google Drive, sobre como corrigir e cortar uma fotografia e diagramar o jornal. No espaço virtual do blog, conviveram com a realidade de produção de conteúdo para a Internet e foram os principais divulgadores da ideia na escola e no bairro.

Os alunos, que inicialmente desafiados, tiveram receio quanto à produção textual, sentiram-se à vontade durante as oficinas e perceberam que, com comprometimento e o auxílio do grupo e do professor, eram capazes de produzir boas redações. Em suas avaliações sobre as oficinas, no Webfólio, deixaram claro que, mesmo tendo dificuldades iniciais, gostariam que o projeto de elaboração do jornal continuasse e que contasse com a participação deles. Alguns depoimentos escritos demonstram isto:

Aluna C: "Espero que o ano que vem tenha de novo porque é muito legal e eu adorei".

Aluna D: "Eu achei o jornal muito bom para mim, espero que a gente possa fazer o número 2".

Aluna E: "Eu achei uma boa oportunidade aprender sobre o jornal. Eu gostei da organização da pauta e acho que todos gostaram também. Se tiver ainda, eu vou participar".

Tais relatos demonstram que os estudantes, mesmo tendo que enfrentar o desafio da produção textual e comprometer-se com a pesquisa e busca de informações para o conteúdo de seu texto, se identificaram com o jornal produzido. O resultado final foi satisfatório para os mesmos e, portanto, assumiram novamente o compromisso de continuar a produzir o jornal. Compromisso este que a escola, em conversa informal com a diretora e professores, pretende transformar num projeto anual e estendido a mais alunos, com a participação de professores e de toda a comunidade escolar.

Afinal, como destacam Faria e Zanchetta Jr. (2011, p. 141), um jornal na escola desenvolve um laço forte de pertencimento ao contexto escolar, tanto por parte do leitor que irá usufruir do periódico nos mais variados formatos (impresso ou online) quanto dos alunos/jornalistas - produtores e sujeitos ativos do processo.

\section{Conclusão}

Por meio do desenvolvimento de um jornal escolar nas versões impressa e online e, principalmente, através das colocações e avaliações realizadas pela comunidade escolar, é notável destacar que uma metodologia que integra tecnologia, leitura e produção textual é um caminho pedagógico possível. Possível e viável pois demonstrou, na prática, ser muito significativo para o aluno em seu processo de ensino e aprendizagem.

Entretanto, para que novas metodologias pedagógicas possam ter vez e espaço no contexto escolar, faz-se necessário a ruptura com modelo tradicional de aprendizagem. E esta ruptura quem poderá realizá-la é o docente, juntamente com toda a comunidade escolar. Como argumentam Santos e Pinto (1992), o jornal escolar requer o desenvolvimento de uma dinâmica que envolva toda a escola. Sem esta dinâmica, que busque o trabalho interdisciplinar e colaborativo, o projeto perde seu sentido e consistência.

A produção de um jornal demonstrou, também, a importância de permitir que o aluno assuma o papel de sujeito na construção do saber e de novos conhecimentos a 
serem compartilhados. Como sujeito de sua prática, desenvolve a condição cognitiva de pensar, investigar, pesquisar, debater e, com isso, ampliar seus conhecimentos, sobretudo o seu próprio conceito sobre a escrita. Ao produzir uma escrita para além dos muros da sala de aula, o aluno se coloca diante de uma condição em que a escrita se torna uma ferramenta importante de comunicação e expressão. Tal condição, num primeiro momento, causa certo desconforto pois desloca-o da passividade do expectador para o de produtor ativo de novos conhecimentos. No entanto, esta transição é fundamental para que o mesmo experimente uma nova forma de conviver com a sua escrita. Uma escrita mais significativa e ligada ao seu tempo e contexto. Uma escrita que expressa, de forma consistente, seu jeito de ser e estar como sujeito numa dimensão histórica e cultural. Escrita com identidade e ligada ao contexto tecnológico do século XXI.

\section{Referências Bibliográficas}

BITENCOURT, Jossiane Boyen; SANTOS, Marlise Bock. Software Livre: Perspectivas Teóricas e Práticas de Utilização na Informática Educacional. Revista Renote - Novas Tecnologias na Educação. Porto Alegre: UFRGS, v. 2, n. 2, nov. 2004. Disponível em: < http://seer.ufrgs.br/renote/article/view/13783>. Acesso em: 02 nov. 2014.

BORDENAVE, J. D.; PEREIRA, A. M. Estratégias de ensino-aprendizagem. 21 ed. Petrópolis: Vozes, 2000. $312 \mathrm{p}$.

CAGLIARI, Luiz Carlos. Alfabetização \& Linguística. 1. ed. São Paulo: Scipione, 2009. 178 p. (Coleção Pensamento e Ação na Sala de Aula) ISBN 9788526278219.

CAVALCANTI, Jauranice Rodrigues. Professor, Leitura e Escrita. São Paulo: Contexto, 2010. 210 p. ISBN 9788572444835.

FARIA, Maria Alice de Oliveira. Como Usar o Jornal na Sala de Aula. 2. ed. São Paulo: Contexto, 2009. 164 p. (Coleção Repensando o Ensino) ISBN 9788572440462.

FARIA, Maria Alice; ZANCHETTA JR, Juvenal. Para Ler e Fazer o Jornal na Sala de Aula. 3. ed. São Paulo: Contexto, 2011. 182 p. ISBN 9788572441957.

FREINET, C. Para uma escola do povo. Tradução de Arlindo Mota. Lisboa: Presença, 1969. FREINET, C. As técnicas Freinet da escola moderna. Tradução de Silva Letra. Lisboa: Stampa, 1976.

FREINET, C. Ensaio de psicologia sensível. 1. ed. Tradução de Cristina Nascimento e Maria Ermantina

GOMES, Rejane Radtke. A Importância da Descrição e Análise dos "Erros": Como Identificar e Trabalhar as Dificuldades recorrentes na Escrita dos Alunos. 2012. 25 f. Artigo (Especialização em Letras) - Universidade Federal de Pelotas, Programa de Pós-Graduação em Letras, Pelotas, 2012. Disponível em: $<$ http://wp.ufpel.edu.br/letras-pos/especializacao/files/2012/02/A-import $\% \mathrm{C} 3 \% \mathrm{~A} 2$ ncia-da-descri\% $\% 3 \% \mathrm{~A} 7 \% \mathrm{C} 3 \% \mathrm{~A} 30$-e-an\%C3\%A1lise-dos-erros-como-identificar-etrabalhar-as-dificuldades-recorrentes-na-escrita-dos-alunos.pdf $>$. Acesso em: 6 nov. 2014.

LÉVY, P. O que é virtual? Rio de Janeiro: Editora 34, 1998.

PAVIANI, J. Interdisciplinaridade: Conceito e Distinções. Porto Alegre: Edições Pyr, 2005. PIAGET, J. Psicologia da inteligência. Rio de Janeiro: Fundo de Cultura, 1956.

SANTOS, António; PINTO, Manuel. O Jornal Escolar: Porque e como Fazê-lo. 1. ed. Porto: Edições ASA, 1992. 87 p. (Coleção Cadernos Pedagógicos, v.1) ISBN 9724110710.

TRAVAGLIA, Luiz Carlos. Gramática e Interação: Uma Proposta para o Ensino de Gramática. 14. ed. São Paulo: Cortez, 2009. 248 p. (Coleção Temáticas de Gramática) ISBN 9788524909825.

VYGOTSKY, L. S. El desarrollo de los procesos psicológicos superiores. Barcelona: Crítica, 1979.

VYGOTSKY, L. S. Pensamento e linguagem. São Paulo: Martins Fontes, 1989. VYGOTSKY, L. S. A formação social da mente. São Paulo: Martins Fontes, 1998. 